\title{
Effect of Seasonality and Ecological Factors on the Prevalence of the Four Malaria Parasite Species in Northern Mali
}

\author{
Ousmane A. Koita, ${ }^{1}$ Lansana Sangaré, ${ }^{1}$ Hammadoun A. Sango, ${ }^{2}$ Sounkalo Dao, ${ }^{3}$ \\ Naffet Keita, ${ }^{4}$ Moussa Maiga, ${ }^{3}$ Mamadou Mounkoro, ${ }^{1}$ Zoumana Fané, ${ }^{5}$ \\ Abderrhamane S. Maiga, ${ }^{6}$ Klénon Traoré, $^{5}$ Amadou Diallo, ${ }^{1}$ and D. J. Krogstad ${ }^{7}$ \\ ${ }^{1}$ Laboratoire de Biologie Moléculaire Appliquée, Faculté des Sciences et Techniques, Université de Bamako, BP 2191, Bamako, Mali \\ ${ }^{2}$ Département d'Epidémiologie et de Santé Publique, Faculté de Médecine, Pharmacie et d'OdontoStomatologie, Université de Bamako, \\ BP 1805, Bamako, Mali \\ ${ }^{3}$ Service des Maladies Infectieuses, Hôpital National du Point G, BP 1805, Bamako, Mali \\ ${ }^{4}$ Direction Régionale de la Santé de Gao, Ministère de la Santé, BP 232, Gao, Mali \\ ${ }^{5}$ Faculté des Langues des Arts et des Sciences Humaines, Université de Bamako, BP E 3637, Bamako, Mali \\ ${ }^{6}$ Institut National de Recherche en Santé Publique, BP 1771, Bamako, Mali \\ ${ }^{7}$ Department of Tropical Medicine, School of Public Health and Tropical Medicine, Tulane University, New Orleans, LA 70112, USA
}

Correspondence should be addressed to Ousmane A. Koita, okoita@icermali.org

Received 25 April 2011; Accepted 29 December 2011

Academic Editor: Sasithon Pukrittayakamee

Copyright ( $) 2012$ Ousmane A. Koita et al. This is an open access article distributed under the Creative Commons Attribution License, which permits unrestricted use, distribution, and reproduction in any medium, provided the original work is properly cited.

\begin{abstract}
Background. We performed 2 cross-sectional studies in Ménaka in the Northeastern Mali across 9 sites in different ecological settings: 4 sites have permanent ponds, 4 without ponds, and one (City of Ménaka) has a semipermanent pond. We enrolled 1328 subjects in May 2004 (hot dry season) and 1422 in February 2005 (cold dry season) after the rainy season. Objective. To examine the seasonality of malaria parasite prevalence in this dry northern part of Mali at the edge of the Sahara desert. Results. Slide prevalence was lower in hot dry than cold dry season (4.94 versus $6.85 \%, P=0.025)$. Gametocyte rate increased to $0.91 \%$ in February. Four species were identified. Plasmodium falciparum was most prevalent $(74.13$ and $63.72 \%)$. P. malariae increased from $9.38 \%$ to $22.54 \%$ in February. In contrast, prevalence of $P$. vivax was higher $(10.31 \%)$ without seasonal variation. Smear positivity was associated with splenomegaly $(P=0.007)$. Malaria remained stable in the villages with ponds $(P=0.221)$; in contrast, prevalence varied between the 2 seasons in the villages without ponds $(P=0.004)$. Conclusion. Malaria was mesoendemic; 4 species circulates with a seasonal fluctuation for Plasmodium falciparum.
\end{abstract}

\section{Introduction}

Malaria is still an overwhelming public health problem in the sub-Saharan Africa, more than $90 \%$ of the disease burden occurs in Africa [1]. Children under 5 years of age and pregnant women constitute the major groups for developing life-threatening situation in malaria [2]. Case fatality rates for cerebral malaria and severe anemia among children have been estimated, respectively, 19 and 13\% [3]. Acquisition of immunity against malaria infection requires a long exposure to infective bite of anopheline mosquitoes [4] and the number of those infective bites depends on several factors such as human host, parasite genetic make-up, and ecology [5].

Thus, distribution of malaria relies on ecological factors such as rainfall in the Sahel; anopheline mosquito, the vector of malaria, responsible for transmitting the parasite from one host to another needs enough water to breed. Based on previous studies $[6,7]$, it has been observed that prevalence of malaria infection ranges from $70-85 \%$ in the south of Mali with $1,000 \mathrm{~mm}$ of annual rain to $0.5 \%$ in the north [8] where the annual rainfall is below $400 \mathrm{~mm}$. Sahara constitutes a buffer zone between the southern part of Africa and the Mediterranean border. In contrast to the wet southern part, 
the belief is that malaria does not exist in the Sahara or can be epidemic [9]. However, bodies of water like ponds are scattered through this region and constitute settlements for nomadic people. Malaria epidemic may occur in such establishment among susceptible population with housing easily accessible to mosquitoes [10]. Strategies to control malaria must be based on epidemiological entities; therefore all parameters should be assessed in each distinct ecological zone to rationalize the use of scarce resources. Several studies were carried out in southern part of Mali which provide prevalences of infection during the rainy and dry seasons, varying from $85 \%$ to $55 \%$, respectively $[6,7]$, and only 3 species of malaria parasites have been described. P. malariae represents only 2 to $3 \%$ of infected patients and no infection with $P$. vivax was observed in dark skin subjects during all parasitological investigations carried out so far in Mali. The northern Mali is land of nomadic populations (Tuaregs and Maures) who move around ponds, oueds, and water forages; no epidemiological studies were performed in a prospective manner to identify dynamic of circulating parasites in those areas and to evaluate parasitological parameters of malaria in the North of Mali. Thus, we carried out a crosssectional study to examine the seasonality of malaria parasite prevalence during dry hot (May 2004) and cold (February 2005) seasons in the District of Ménaka located in the NorthEastern part of Mali.

\section{Materials and Methods}

2.1. Study Area. The District of Ménaka is located in the northern-East between longitude $1^{\circ} 20$ and $4^{\circ} 15$ East and latitude $15^{\circ} 20$ and $18^{\circ}$ north. It is limited by Tinessako (Region of Kidal) in the North, Niger in the East, and by Ansongo in the West (Figure 1). The height above sea level varies between 280 and $350 \mathrm{~mm}$. There are two main seasons (dry and rainy). In dry season, Ménaka is arid with average of temperature of $38^{\circ} \mathrm{C}$ (varying from 25 to $45^{\circ} \mathrm{C}$ ); it begins from November to May and the rainy season from June to October. Annual rainfall oscillates between $150 \mathrm{~mm}$ in the North and $300 \mathrm{~mm}$ in the South. This study has been carried out in 9 rural communes and the district of Ménaka. Population of Ménaka is in majority farmers and nomadic breeders [11]. According to the administrative census of 1998, population of Ménaka counts about 73116 inhabitants with a density less than one inhabitant per $\mathrm{km}^{2}$. Since 1998, 18\% of the populations settled permanently in cities of Ménaka, Andéramboukane, and Inékar. The rest of the population $(82 \%)$ settled in the nomadic camps around the ponds. The main ethnic group is Kel Tamacheq (nomadic inhabitants), they are about $95 \%$, and the minority groups are seminomadic Sonrhaïs, Haoussas, and Maures. The Daoussahaqs are persons of mixed race of Touaregs and Sonrhaï and speak a dialect close to these two languages. They represent the majority of the active population in sectors of agriculture and cattle breeding [11].

2.2. Sample Size and Study Populations. We have carried out a random sampling by relying on subjects who were present at the time of our passage in each site until we reached the estimated number of subjects planned for the study. Based on our stratification, 108 subjects may constitute one unit. A total of 1328 subjects of 12 clusters (108 units per cluster) have been screened for malaria infection in May 2004 in 9 rural and district sites of Ménaka prefecture. We performed 8 months after a second passage in February by including 1422 subjects with 108 units per cluster.

2.3. Clinical Examination. Each subject was examined by a physician at teach study site (village). Body axillary's temperature was recorded using an electronic thermometer (ThermoScan, Whyllen) and spleen enlargement was assessed based on Hackett's criteria [12].

2.4. Thin and Thick Smears. Thick and thin smears were collected from the fingerstick and then were stained with $3 \%$ giemsa (Sigma, St. Louis, MO) in phosphate buffer $(\mathrm{pH} 7.0)$ and examined using oil immersion magnification (1000x). Each slide was examined by two microscopists, who estimated the parasite density by counting the number of asexual $P$. falciparum parasites in fields containing 300 white blood cells, and multiplied that number by 25 to estimate the number of asexual $P$. falciparum parasites per $\mu \mathrm{L}$ (based on an average white blood cells count of 7500 per $\mu \mathrm{L}-[13])$. Slides were considered positive or negative after two readers examined fields containing 300 white blood cells. Slides on which there was disagreement were examined by a third microscopist.

2.5. Collection of Filter Paper Blots. Freshly blotted filter papers obtained from each subject were dried in a closed cardboard box to protect them from flies and dust. Each filter paper was then labeled with the subject's study number, placed in an envelope labeled with the same number, and stored at ambient temperature in a file cabinet.

2.6. Hematocrit Measurement. A capillary tube (VWR, West Chester, Pa) covered of heparin (anticoagulant) was filled of blood to the feature of calibration. Then, one of the ends was stopped with wax. The blood contained in each capillary tube of each subject was then separated after centrifugation with the Thermo MicroMB centrifuge (Thermo IEC, Needham Heights, MA, USA). Reading was performed according to instructions' of manufacturer using circular microcapillary tube reader (IEC, Needham Heights, MA, USA). In this study, anemia was defined when the hematocrit rate is less than 33 [14].

2.7. DNA Amplification Using the Polymerase Chain Reaction $(P C R)$. Plasmodium vivax parasite DNA was extracted from filter paper blots with Chelex-100 method as previously described [15]. Using primers specific for the $5^{\prime}$ and $3^{\prime}$ regions of the MSP-1 for $P$. vivax that flank the repeat region, Nested PCR amplification was performed as described by Alger [16].

2.8. Data Analysis. Excel software (Microsoft office 2003) has been used for data entry, the statistical analysis with the SPSS 


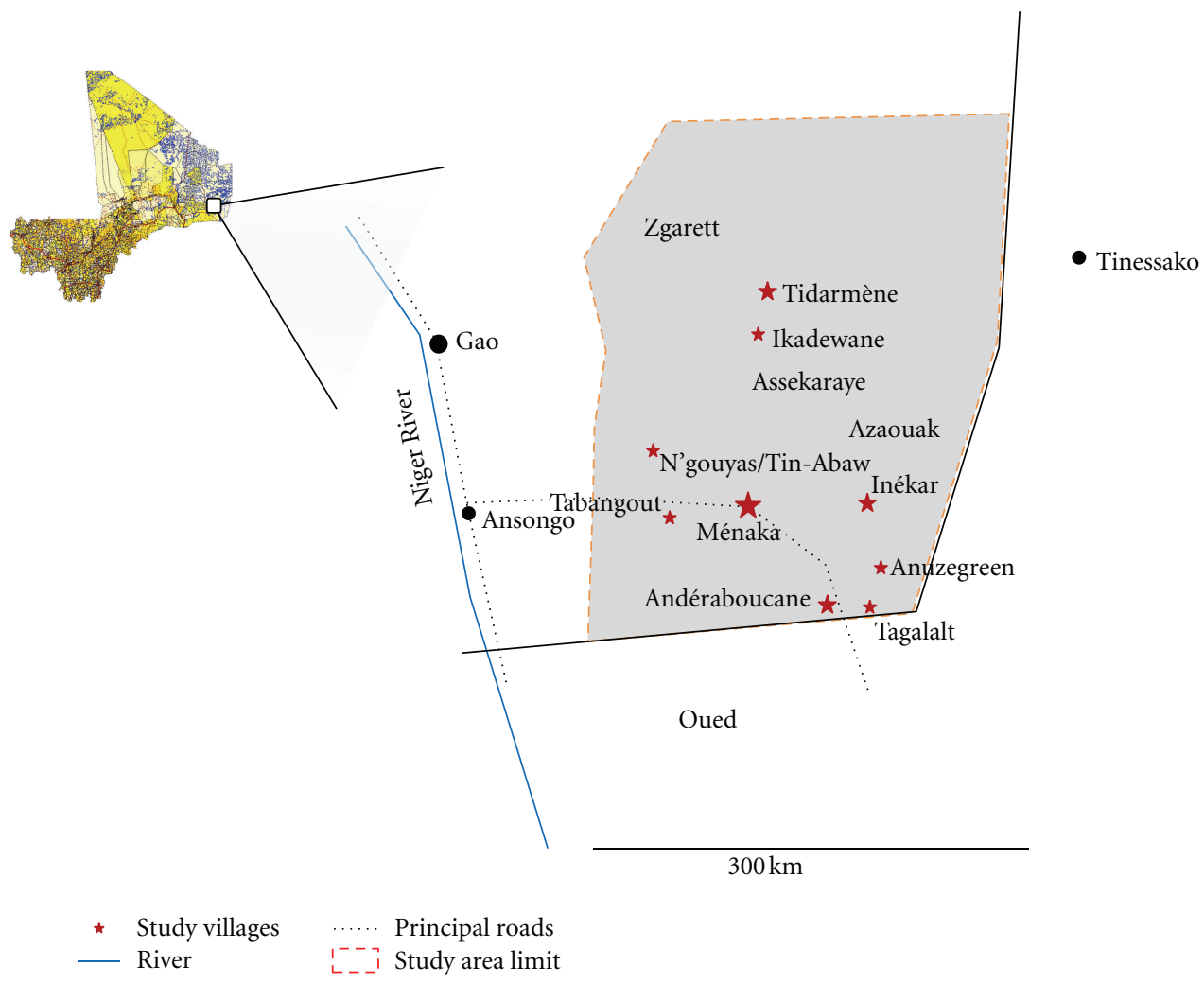

FIGURE 1: Map of study area. This map shows the 9 sites where the study was performed. Andéramboukane (has a permanent pond) and Talgalat (semipermanent pond, dry at the end of the year) are located near the border with the Republic of Niger (North of Mali). Tin-abaw and and N'gouyass separated by a permanent pound are located between Ménaka and Andéramboukane. Inekar and Anuzegreen that are also located between Menaka and Andéramboukane do not have ponds. Sites such as Tabangout (10 km from Ménaka) and TidarmaneIkadewane that are situated in the south of Ménaka, do not have ponds. Ménaka, the capital city, has a semipermanent pond.

software (Version 11.0 for Window). Pearson chi-square test or Fisher test has been used for prevalence comparison between data obtained in 2004 and 2005. Unpaired $t$-test was performed to compare if there was a difference in terms of the size population between the dry hot season (2004) and dry cold season (2005). The odds ratio test has been estimated to seek the relationship between malaria species and symptoms. A $P$ value less than 0.05 was considered as significant.

2.9. Ethical Consideration. Protocol was first submitted and approved by the Ministry of Health (Bamako, Mali) and then explained to village's council. After its approval, each participant was then informed about the protocol; care was given to all study participants. Oral informed consent or assent (for children less than 18 years of age) was then obtained from each participant.

\section{Results}

We performed 2 cross-sectional passages, one during the dry season just one month prior to the rainy season which begins between June and July. The second survey was conducted in February 3 months after the rainy season ending in October. We could not perform the study during the rainy season because most of children enrolled in the study
(May 2004 and February 2005) were in the school summer break which occurs during the malaria transmission season (June-September) and were not accessible. However, data collected during the dry and cold periods allowed us to examine the fluctuation of parasitological parameters among populations in the 9 sites of Ménaka. There was not a significant difference between our study populations during the 2 passages (Table 1 ). Thus, 1328 subjects were included in May 2004 versus 1422 in February 2005. No statistical variation was observed among populations of the 9 sites during the 2 passages (Table 1). In addition, subjects between 0 and 9 years of age were comparable during the 2 passages (May 2004 and February 2005) with a $P$ value $=0.868$ (unpaired $t$-test). Similarly, subjects with age greater than 9 years were also comparable between the 2 passages (May 2004 and February 2005) with $P$ value $=0.866$ (Table 1).

Comparing the data obtained from the studied populations in 2004 and 2005 (Table 2), there was a significant difference between age groups and the presence of ponds (or absence of ponds), we observed that there were more children in the areas with ponds than areas without ponds $(P<0.0001)$. The same trends were observed with the type of skin (derma); there were more subjects with dark skin in the areas with ponds than areas without ponds during the years 2004 and $2005(P<0.0001)$. There were more females 
TABLE 1: Study population repartition by age group in May 2004 (Dry season) and in February 2005 (Cold season).

\begin{tabular}{|c|c|c|c|c|c|c|c|c|c|c|c|c|}
\hline \multirow{3}{*}{ Sites of study } & \multicolumn{6}{|c|}{$0-9$ years old } & \multicolumn{6}{|c|}{$>9$ years old } \\
\hline & \multicolumn{2}{|c|}{ May 2004} & \multicolumn{2}{|c|}{ February 2005} & \multirow[b]{2}{*}{$P$} & \multirow[b]{2}{*}{ Total } & \multicolumn{2}{|c|}{ May 2004} & \multicolumn{2}{|c|}{ February 2005} & \multirow[b]{2}{*}{$P\left(\chi^{2}\right.$ test $)$} & \multirow[b]{2}{*}{ Total } \\
\hline & $N$ & $(\%)$ & $N$ & $(\%)$ & & & $N$ & $(\%)$ & $N$ & $(\%)$ & & \\
\hline Tidarmène-Ikadewane & 47 & 52.5 & 132 & 57.4 & 0.602 & 108 & 61 & 56.5 & 98 & 42.6 & 0.113 & 230 \\
\hline Ménaka & 203 & 62.2 & 44 & 37 & 0.001 & 326 & 123 & 37.7 & 75 & 63 & 0.0005 & 119 \\
\hline Inékar & 45 & 32.8 & 42 & 36.2 & 0.815 & 113 & 68 & 60.2 & 74 & 63.8 & 0.693 & 116 \\
\hline Anuzegreen & 40 & 36.7 & 230 & 66.7 & 0.0004 & 109 & 69 & 63.3 & 115 & 33.3 & 0.00004 & 345 \\
\hline Tagalalt & 37 & 33.3 & 41 & 28.9 & 0.762 & 111 & 74 & 66.7 & 101 & 71.1 & 0.473 & 142 \\
\hline Andéramboukane & 44 & 20.2 & 33 & 28.7 & 0.484 & 218 & 174 & 79.8 & 82 & 71.3 & 0.104 & 115 \\
\hline N'gouyas & 71 & 61.7 & 34 & 28.6 & 0.001 & 115 & 44 & 38.3 & 85 & 71.4 & 0.0002 & 119 \\
\hline Tin-abaw & 59 & 51.3 & 24 & 20.9 & 0.012 & 115 & 56 & 48.7 & 91 & 79.1 & 0.0001 & 115 \\
\hline Tabangout & 29 & 25.7 & 39 & 34.2 & 0.41 & 113 & 84 & 74.3 & 75 & 65.8 & 0.245 & 114 \\
\hline Total & 575 & 43.3 & 619 & 43.7 & 0.868 & $1328^{*}$ & 753 & 56.7 & 796 & 56.3 & 0.866 & $1415^{*}$ \\
\hline
\end{tabular}

* Those numbers are different from the populations we screened because we pulled out the subjects having age as missing value.

In overall, there was not a significant difference among the children less than 9 years of age between May 2004 and February $2005(P=0.868)$. In addition, the same observation was also noticed among subjects more than 9 years of age $(P=0.866)$. Subjects between 0 and 9 years of age were comparable during the 2 passages (May 2004 and February 2005) with a $P$ value $=0.868$. Similarly, subjects with age greater than 9 years were also comparable between the 2 passages (May 2004 and February 2005) with $P$ value $=0.866$.

TABLE 2: Demographic characteristics of study populations.

\begin{tabular}{|c|c|c|c|c|}
\hline $\begin{array}{l}\text { Demographic } \\
\text { characteristics }\end{array}$ & & Ponds & No ponds & $P$ value (Fisher test) \\
\hline \multicolumn{5}{|l|}{2004} \\
\hline \multirow[t]{2}{*}{ Age group } & $0-9$ & 414 & 161 & $<0.0001$ \\
\hline & $>9$ & 270 & 448 & \\
\hline \multirow[t]{2}{*}{ Sex } & Male & 500 & 209 & 0.002 \\
\hline & Female & 385 & 234 & \\
\hline \multirow[t]{2}{*}{ Derma } & Light skin & 313 & 218 & $<0.0001$ \\
\hline & Dark skin & 573 & 225 & \\
\hline \multicolumn{5}{|l|}{2005} \\
\hline \multirow[t]{2}{*}{ Age group } & $0-9$ & 476 & 143 & $<0.0001$ \\
\hline & $>9$ & 474 & 322 & \\
\hline \multirow[t]{2}{*}{ Sex } & Male & 494 & 238 & 0.652 \\
\hline & Female & 457 & 233 & \\
\hline \multirow[t]{2}{*}{ Derma } & Light skin & 317 & 242 & $<0.0001$ \\
\hline & Dark skin & 634 & 229 & \\
\hline
\end{tabular}

This table shows that in 2004 and 2005, there was a significant difference between age groups and the presence of ponds (or absence of ponds); we observed that there were more children in the areas with ponds than areas without ponds $(P<0.0001)$. The same trends were observed with the type of skin $($ derma); there were more subjects with dark skin in the areas with ponds than areas without ponds during the years 2004 and $2005(P<0.0001)$. There were more females in the areas with ponds than areas with ponds than areas without ponds in $2004(P=0.002)$; in contrast there was no significant difference between gender and presence of (absence) ponds in $2005(P=0.625)$. 
TABLE 3: Malaria infection prevalence and morbidity in May 2004 and February 2005.

\begin{tabular}{lccccc}
\hline & \multicolumn{2}{c}{ May 2004 } & \multicolumn{2}{c}{ February 2005 } & $P$ value (Fisher and $\chi^{2}$ tests) \\
Plasmodium specie frequencies & $N(\%)$ & Total & $N(\%)$ & Total & \\
\hline P. falciparum & $50(74.13)$ & 64 & $56(63.72)$ & 97 & $0.0124^{*}$ \\
P. malariae & $6(9.38)$ & 64 & $21(22.54)$ & 97 & $0.0419^{*}$ \\
P. ovale & $2(3.13)$ & 64 & $2(2.06)$ & 97 & 0.9258 \\
P. vivax & $5(7.81)$ & 64 & $10(10.31)$ & 97 & $>0.9999$ \\
P. falciparum + P. malariae & $1(1.56)$ & 64 & $7(7.21)$ & 97 & 0.2060 \\
P. falciparum + P. vivax + P. ovale & $0(0)$ & 64 & $1(1.03)$ & 97 & N/A \\
Malaria infection and morbidity & & & & & $0.0259^{*}$ \\
Plasmodic Index & $64(4.95)$ & 1293 & $100(7.06)$ & 1415 & 0.2364 \\
Gametocytic Index & $6(0.46)$ & 1293 & $13(0.91)$ & 1415 & 0.3660 \\
Anemia & $110(8.50)$ & 1293 & $106(7.49)$ & 1415 & 0.2557 \\
Fever & $308(23.82)$ & 1293 & $310(21.90)$ & 1415 & $0.0077^{*}$ \\
Splenomegaly & $64(4.94)$ & 1293 & $41(2.89)$ & 1415 & $<0.000001^{*}$ \\
Overall malaria symptoms & $42(3.24)$ & 1293 & $343(24.24)$ & 1415 & \\
\hline
\end{tabular}

${ }^{*}$ Significant $P$ value.

Plasmodium falciparum species decreased significantly in February $(P=0.0124)$; in contrast, there was a marked increased in the frequency $P$. malariae in February $(P=0.0419)$. P. ovale and $P$. vivax remained stable between May 2004 and February 2005 (Fisher's exact test, $P>0.05)$. Plasmodic index increased remarkably in February $2005(P=0.0259)$; in contrast, the gametocytic index did not vary significantly between March and February but increased in February $(P=0.2364)$. Symptoms such as anemia and fever did not vary significantly between March and February $(P>0.05)$. Splenomegaly decreased significantly in February $2005(P<0.000001)$.

in the areas with ponds than areas without ponds in 2004 $(P=0.002)$; in contrast there was no significant difference between gender and presence of (absence) ponds in 2005 $(P=0.625)$.

Parasitological data showed that the 4 species were circulating in Ménaka. Overall prevalence varied from 4.95\% in May 2004 (with 64 positive slides in 1293 screened subjects) to $7.06 \%$ in February 2005 (with 97 positive smears among 1422 subjects). This seasonal variation in prevalence of malaria infection was statistically significant (Table 3 , $P=0.0259)$. However, we could not find any statistically difference between gametocyte prevalence between the 2 periods although the prevalence was higher in cold season with $0.91 \%$ (13 out of 1415 ) versus $0.46 \%$ (6 out of 1293 ) in dry season (Table $3, P=0.2364$ ).

Plasmodium falciparum was the most prevalent in dry season (2004) as well as in cold period (2005), but with a higher proportion in dry season $74.13 \%$ versus $63.72 \%$ in cold season. In 64 infections (2004), 50 were due to P. falciparum (Table 3). This proportion decreased during the cold season. Among 97 positive infections with malaria parasites, 56 (63.72\%) were caused by P. falciparum (Table 3). This variation in terms of $P$. falciparum species prevalence between cold and dry season was statistically significant (Table 3, $P=0.03$ ).

Prevalence of $P$. malariae infection increased considerably in cold season. Six infections were due to this species among 64 infected subjects with the 4 species $(9.38 \%)$ in dry season while among 97 infected persons in cold period, 21 were caused by P. malariae (21.64\%). There was a significant difference in prevalence of $P$. malariae infection between May 2004 and February 2005 (Table 3, $P=0.0419$ ).
Plasmodium ovale and $P$. vivax infections represented $3.13 \%(2 / 64)$ and $7.81 \%(5 / 64)$, respectively, in dry season. In cold season, even though the frequency of $P$. vivax was higher $10.31 \%(10 / 97)$, there was not a statistically variation between May 2004 and February 2005 (Table 3, Fisher's exact test $P>0.05$ ).

We observed 2 cases of mixed infections, one case of $P$. falciparum and P. malariae was identified in dry season (2004) among the 64 positive slides (1.56\%), and the number increased to 7 out of 97 positive slides in cold season (2005) with $7.21 \%$ (Table 3, Fisher's exact test $P=0.147$ ). One case of mixed of 3 species (P. falciparum, P. ovale, and P. vivax) was identified only in the cold season in 2005 (Table 3).

Prevalence of enlarged spleen was higher during the dry season with 5\% (64/1264) than during the cold period with $2.9 \%$ (41/1397), and this difference was statistically significant (Table $3, P=0.006$ ).

Clinical symptoms such anemia and fever did not vary significantly between seasons. It was $10.4 \%(141 / 1328)$ and $10.5 \%$ and $22.2 \%$, respectively, for anemia and fever $(P=$ 0.97 and 0.95 for the 2 symptoms; Table 3 ).

Relationship between age groups and parasite prevalence was assessed (Table 4); we observed no statistically difference between the 2 passages although the frequency of infection was higher in May among subjects between 0 and 9 years of age with $8.69 \%(50 / 575)$ than in those observed in February with $5.97 \%$ (37/619), and $P$ value was 0.0753 . In contrast, more subjects with age greater than 9 years of age were infected in February than in May, 7.5\% (60/796) versus $1.94(14 / 718)$, respectively, and this difference was significant $(P=0.000001)$. Interestingly between the cold (2005) and dry (2004) seasons, children from 0 to 9 years 
TABLE 4: Relationship between the age group and plasmodic index.

\begin{tabular}{|c|c|c|c|c|c|c|c|}
\hline \multirow[t]{2}{*}{ Age (in years) } & \multicolumn{3}{|c|}{2004} & \multicolumn{3}{|c|}{2005} & \multirow{2}{*}{$\begin{array}{l}P \text { value } \\
\left(\chi^{2} \text { test }\right)\end{array}$} \\
\hline & Positives & $(\%)$ & Total & Positives & $(\%)$ & Total & \\
\hline $0-9$ & 50 & $(8.69)$ & 575 & 37 & $(5.97)$ & 619 & 0.0753 \\
\hline$>9$ & 14 & $(1.94)$ & 718 & 60 & $(7.53)$ & 796 & $<0.0001$ \\
\hline Total & 64 & $(4.94)$ & 1293 & 97 & $(6.85)$ & 1415 & 0.0441 \\
\hline$P$-value (Fisher's exact test) & & $<0.0001$ & & & 0.2890 & & \\
\hline
\end{tabular}

The plasmodic index varied significantly from May 2004 to February 2005 in the older people (age greater than 9 years of age) than the group of children between 0 and 9 years of age (Fisher's exact test, $P=0.0001$ ). In overall, there was a significant change in plasmodic index between May 2004 and February $2005\left(\chi^{2}=4.052 ; P=0.0441\right)$. It was greater in February 2005 with $6.85 \%$ versus $4.94 \%$ in May 2004 .

TABLE 5: Infection prevalence of malaria by site with the presence of pounds and without.

\begin{tabular}{|c|c|c|c|c|}
\hline \multirow[t]{2}{*}{ Villages } & \multicolumn{2}{|c|}{ May 2004} & \multicolumn{2}{|c|}{ February 2005} \\
\hline & $N(\%)$ & Total & $N(\%)$ & Total \\
\hline \multicolumn{5}{|l|}{ Presence of ponds } \\
\hline Andéramboukane & $7(3.2)$ & 218 & $14(6.1)$ & 230 \\
\hline Ménaka & $39(12)$ & 326 & $14(4.1)$ & 345 \\
\hline N'gouyass & $1(0.87)$ & 115 & $8(5.6)$ & 142 \\
\hline Tin-Abaw & $7(6.1)$ & 115 & $3(2.6)$ & 114 \\
\hline Tagalalt & $7(6.3)$ & 111 & $41(34.2)$ & 120 \\
\hline \multirow[t]{2}{*}{ Total } & $61(6.89)$ & 885 & $80(8.41)$ & 951 \\
\hline & \multicolumn{4}{|c|}{$\chi^{2}=1.49 ; P=0.221$} \\
\hline \multicolumn{5}{|l|}{ Absence of ponds } \\
\hline Tabangout & 0 & 113 & $5(4.3)$ & 115 \\
\hline Tidarmene & $1(0.9)$ & 108 & $2(1.7)$ & 115 \\
\hline Anuzegreen & $0(0.0)$ & 108 & $6(4.8)$ & 125 \\
\hline Inékar & $4(3.5)$ & 113 & $7(6.0)$ & 116 \\
\hline \multirow[t]{2}{*}{ Total } & $5(1.13)$ & 442 & $20(4.24)$ & 471 \\
\hline & \multicolumn{4}{|c|}{$\chi^{2}=8.31 ; P=0.004$} \\
\hline
\end{tabular}

The prevalence was significantly higher in the villages with ponds than the prevalence obtained in the villages without ponds $\left(\chi^{2}=4.771, P\right.$ value $\left.=0.0289\right)$. Within the study sites where the pounds are located, there was not statistically difference between the 2 follow-ups $(P=0.22)$. In contrast, a significant difference was observed among the village without pounds; malaria infection was higher in February in cold dry season (4.24\%) than in May 2004 (1.13\%) in the hot dry season $(P=0.004)$. This table suggests the role of the ponds in the transmission of malaria.

of age and subjects with age greater than 9 years were equally infected; no significant difference was found (Table 4; $P=0.0753)$. In addition, a different picture was observed in May during the dry season; children (0-9 years of age) were frequently infected with $8.69 \%$ (50/575) of malaria parasites than older subjects (age > 9 years) with $1.94 \%$ (14/718). Difference was statistically significant with $P=$ 0.0001 (Table 4). Comparing the plasmodic index within 2005, between 0 and 9 years of age and subjects having more than 9 years of age, the difference was not statistically significant (Table 4, $P=0.2890$ ). We have investigated whether there was a difference in prevalence of parasite infection based on presence of ponds in study's sites. When we compared malaria prevalence in sites with ponds, no statistical difference in May and February $(P=0.221)$ was observed. In contrast, there was a statically difference in the prevalence of malaria between cold and dry season in the villages without ponds $(P=0.004)$. By comparing the prevalence of malaria infection in the villages with ponds and villages without ponds, we did find a difference; the prevalence was higher in sites with ponds than without ponds (Table $5, P=0.0289$ ).

To confirm the presence of $P$. vivax in that part of Mali identified by thick smear, we performed Polymerase Chain Reaction using $P$. Vivax merozoite surface protein-1 block 5 and 6 markers. Belem (366 basepairs) and Salvador-1 (429 basepairs) genotypes have been identified in a single individual, confirming that $P$. vivax was circulating in Mali (Figure 2).

We assessed the relationship between anemia and malaria species (Table 6, OR = 4.633 95\% CI [1.826-11.752]), an association between $P$. malariae infection and hemoglobin 


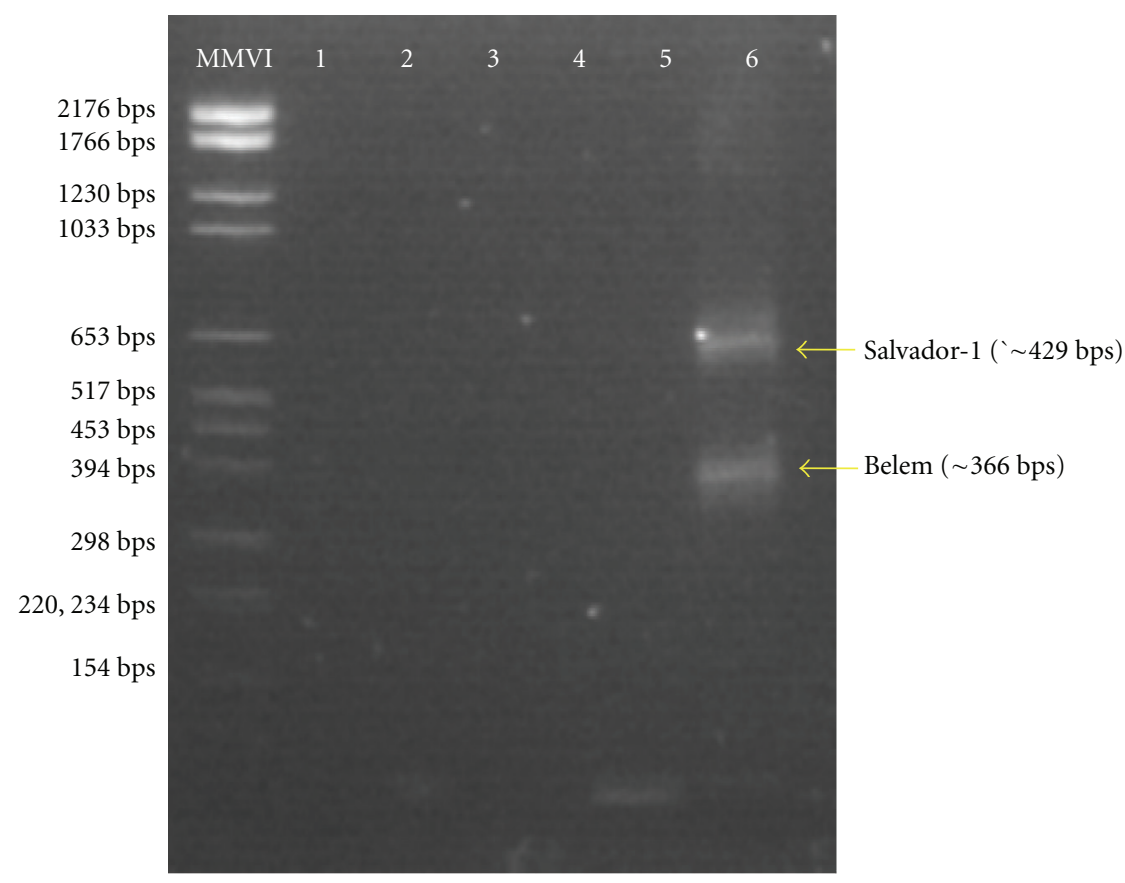

FIgURe 2: Picture of agarose gel with PCR products. This gel shows a $P$. vivax diagnosis confirmation by nested PCR method using primer sequences designed from MSP-5/6 conserved blocks in subject 5 (Andéranboukane 125).

TABle 6: Association between malaria and anemia.

\begin{tabular}{lccc}
\hline P. malariae & Anemia & $(\%)$ & Total \\
\hline Yes & 7 & $(33.3)$ & 21 \\
No & 98 & $(9.7)$ & 1006 \\
\hline Total & 105 & $(10.2)$ & 1027 \\
\hline
\end{tabular}

The prevalence of anemia was 4.6 -fold higher in patients with $P$. malariae $(33.3 \%)$ than in those without $(9.7 \%)$ malariae species infection $(\mathrm{OR}=$ $4.63395 \%$ CI $[1.826-11.752] ; P=0.003)$.

less than $10 \mathrm{~g} / \mathrm{dL}$ was observed, and prevalence of anemia was 4.6-fold higher in subjects with P. malariae infection (33.3\%) than in those with other malaria species $(9.7 \%)$.

\section{Discussion}

We performed 2 cross-sectional studies in Ménaka, which is situated in the Northern part of Mali at the borders with Niger and Algeria. In terms of sample size, the population screened during the passages of May 2004 and February 2005 was comparable (Table 1). However, we observed a different trend of parasite prevalence; prevalence of infection (smear positivity) was lower during the hot dry season than the cold dry season (4.95 versus $7.06 \%, P=0.003$ ). This fluctuation could be explained by ecological factors such as ponds that contribute to the transmission of malaria parasites beside the rainy season [17-19]. This prevalence suggests that Ménaka must be considered as zone of hypoendemicity for malaria transmission.

Higher prevalence of malaria infection obtained in February 2005 three months after the conclusion of the rainy period may be associated with the presence of ponds in sites with higher prevalence. In addition, prevalence was stable between hot dry period and cold dry season, and no statistically significant variation in parasite prevalence was observed between sites with ponds $(P=0.221)$. In contrast, there was a significant difference in prevalence of malaria infection in the sites without ponds $(P=0.004)$, the prevalence being higher in cold season than during the hot period. Those data taken together will allow one to hypothesize that ponds serve as breeding sites for mosquitoes, which are able to maintain transmission of malaria parasites in absence of rains in the dry part of the country. Guthmann et al. [20] made the relationship between expansion of ponds and increase of malaria incidence. A 50-fold increase of malaria incidence coincided with development of pond surface in the Iquitos region of Peru.

The four species of malaria parasites have been observed during the 2 passages (May 2004 and February 2005); however the proportion of infected people with the four species varied seasonally. $P$. falciparum was most prevalent (74.13 and $63.72 \%$ ), followed by P. malariae, which increased from 9.38 during the dry hot season (May) to $22.54 \%$ after the rainy season in February. The high prevalence of P. malariae observed in February was unusual; all studies performed in Mali show that the prevalence was always less than $10 \%[7,21]$. Thus, we suggest that anopheline mosquitoes associated to ponds could be different in transmitting P. malariae than those found in South associated mainly with the rainfall. However, entomological studies are needed to identify anopheline species, which breed around the ponds and assess their vectorial capacity. The only data on anopheline mosquitoes were from the north of Mali 
and obtained between Gao and the border of Algeria; they indicated that Anopheles gambiae complex and Anopheles pharaonsis were present [8]. Frequency of $P$. vivax and $P$. ovale remained stable over the 2 periods. Interestingly, the prevalence of $P$. vivax was higher with $\sim 10 \%$ of infection compared with to the data collected along the Transsaharan road from Bourem to Tessalit at the border with Algeria. In that region, Koita [8] observed that less than $1 \%$ of infection is due to $P$. vivax. The stability in the prevalence of $P$. vivax and $P$. ovale could be explained in part by recurrent infection with the release of hypnozoites [22] from the liver on which there is no treatment available in our 9 study sites. Our PCR data confirmed the data obtained by microscopy about the circulation of $P$. vivax at the edge of Sahara desert. Two genotypes Belem (366 basepairs) and Salvador-1 (429 basepairs) have been identified in a single infection. Presence of $P$. vivax parasite in that region was expected, because in that part of Mali live Duffy positive population, who are susceptible to $P$. vivax infection [23]. Our result contrasts with the data obtained in other sub-Saharan Africa countries. Culleton and his colleagues [21] found only $1.4 \%$ of $P$. vivax infections in 9 countries in West and Central Africa. This higher prevalence could be explained by the existence of a proportion of Duffy positive subjects in our study population which turns around 40\% (Table 2, data not shown).

Although prevalence of anemia was lower compared to that found in South of the country [24], subjects with hemoglobin less than $10 \mathrm{~g} / \mathrm{dL}$ were infected frequently with $P$. malariae. We observed that children less than 9 years of age were frequently exposed than older subjects during the dry season; however we did not find a difference among our agegroups after the rainy season. This suggests that age is not a factor in preventing Plasmodium infection; each subject was at risk for infection at this period of year.

\section{Conclusion}

Four species of malaria parasite are in circulation in the northeastern of Mali with a seasonal fluctuation of $P$. falciparum. The prevalence of $P$. vivax (9.2\%) and $P$. ovale remained stable and was not affected by the season. Two genotypes of Plasmodium vivax, Belem and Salvator-1, were identified. The presence of $P$. vivax species is related to the presence of Duffy positive populations in that area of Mali. The results suggest that the presence (or absence) of ponds is an overwhelmingly important factor. In contrast to the situation in the more southern (savannah) part of Mali, they also suggest that the significance of seasonal changes is apparent only in communities without ponds.

\section{Acknowledgments}

The authors are grateful to there guide Tamou, the Prefet of Ménaka, the mayor of each commune, and the Head physician and laboratory technicians of the Health Center of Ménaka. They are undoubtedly grateful to Dr. Sissoko who was instrumental in the relation between the team of the population. This paper has received the financial support from the Health Program Development (PRODESS) at the Direction Régionale de la Santé de Gao (Mali), University of Bamako, and Tulane University. This work is Presented in part at the 54th Annual Meeting of the American Society of Tropical Medicine and Hygiene, Abstract no. 859, Washington DC, December 2005.

\section{References}

[1] J. G. Breman, M. S. Alilio, and A. Mills, "Conquering the intolerable burden of malaria: what's new, what's needed: a summary," American Journal of Tropical Medicine and Hygiene, vol. 71, no. 2, pp. 1-15, 2004.

[2] WHO, "World Malaria Report," 2010, http://www.who.int/ malaria/high_risk_groups/en/.

[3] S. C. Murphy and J. G. Breman, "GAPS in the childhood malaria burden in Africa: cerebral malaria, neurological sequelae, anemia, respiratory distress, hypoglycemia, and complications of pregnancy," American Journal of Tropical Medicine and Hygiene, vol. 64, no. 1-2, supplement, pp. 5767, 2001.

[4] K. Fruh, O. Doumbo, H. M. Muller et al., "Human antibody response to the major merozoite surface antigen of Plasmodium falciparum is strain specific and short-lived," Infection and Immunity, vol. 59, no. 4, pp. 1319-1324, 1991.

[5] D. Ruiz, G. Poveda, I. D. Vélez et al., "Modelling entomological-climatic interactions of Plasmodium falciparum malaria transmission in two Colombian endemicregions: contributions to a National Malaria Early Warning System," Malaria Journal, vol. 5, article 66, no. 1, 2006.

[6] V. Delley, P. Bouvier, N. Breslow et al., "What does a single determination of malaria parasite density mean? A longitudinal survey in Mali," Tropical Medicine and International Health, vol. 5, no. 6, pp. 404-412, 2000.

[7] D. Chabasse, H. Dumon, A. Tounkara, A. Maiga, and P. Ranque, "Malarial indices in 938 children and adolescents in the humid savanna area of the south of Mali," Bulletin de la Société de Pathologie Exotique et de ses Filiales, vol. 73, pp. 254258, 1980.

[8] O. Koita, Contribution à l'épidémiologique du paludisme le long $d u$ tronçon de la route trans-saharienne du Mali, Thèse de Pharmacie, FMPOS, Bamako, Mali, 1989.

[9] A. A. Djimdé, A. Dolo, A. Ouattara, S. Diakité, C. V. Plowe, and O. K. Doumbo, "Molecular diagnosis of resistance to antimalarial drugs during epidemics and in war zones," Journal of Infectious Diseases, vol. 190, no. 4, pp. 853-855, 2004.

[10] A. Sheik-Mohamed and J. P. Velema, "Where health care has no access: the nomadic populations of sub-Saharan Africa," Tropical Medicine and International Health, vol. 4, no. 10, pp. 695-707, 1999.

[11] Programme Minika, Programme d'appui au développement dans les communes de Ménaka, 1996.

[12] D. Metselaar and P. M. van Thiel, "Classification of malaria," Tropical and Geographical Medicine, vol. 11, pp. 157-161, 1959.

[13] D. Payne, "Use and limitations of light microscopy for diagnosing malaria at the primary health care level," Bulletin of the World Health Organization, vol. 66, no. 5, pp. 621-626, 1988.

[14] E. M. DeMaeyer, "Preventing and controlling iron deficiency anemia through primary health care: a guide for health administratoris and programme managers," E. M. DeMaeyer 
and P. Dallman, Eds., World Health Organization, Geneva, Switzerland, 1989.

[15] J. Wooden, E. E. Gould, A. T. Paull, and C. H. Sibley, "Plasmodium falciparum: a simple polymerase chain reaction method for differentiating strains," Experimental Parasitology, vol. 75, no. 2, pp. 207-212, 1992.

[16] J. Alger, Development of molecular markers to distinguish Plasmodium vivax relapse from reinfection, Ph.D. thesis, Tulane University, 1997.

[17] I. M. Kengne Noumsi, A. Akoa, R. A. Eteme et al., "Mosquito development and biological control in a macrophyte-based wastewater treatment plant," Water Science and Technology, vol. 51, no. 12, pp. 201-204, 2005.

[18] F. Seulu, S. Mengistu, H. Fekadu et al., "Larval habitat diversity and ecology of Anopheline larvae in Eritrea," Journal of Medical Entomology, vol. 40, no. 6, pp. 921-929, 2003.

[19] D. Chabasse, C. Roure, A. A. Rhaly et al., "Evaluation of the health status of nomadic and semi-nomadic population of the Gourma-Mali: epidemiology approach-II. Overall results and conclusions," Médecine Tropicale, vol. 43, no. 2, pp. 127135, 1983.

[20] J. P. Guthmann, A. Llanos-Cuentas, A. Palacios, and A. J. Hall, "Environmental factors as determinants of malaria risk. A descriptive study on the northern coast of Peru," Tropical Medicine and International Health, vol. 7, no. 6, pp. 518-525, 2002.

[21] R. L. Culleton, T. Mita, M. Ndounga et al., "Failure to detect Plasmodium vivax in West and Central Africa by PCR species typing," Malaria Journal, vol. 7, article 174, 2008.

[22] D. D. Rajgor, N. J. Gogtay, V. S. Kadam et al., "Efficacy of a 14-day primaquine regimen in preventing relapses in patients with Plasmodium vivax malaria in Mumbai, India," Transactions of the Royal Society of Tropical Medicine and Hygiene, vol. 97, no. 4, pp. 438-440, 2003.

[23] L. H. Miller, S. J. Mason, D. F. Clyde, and M. H. McGinniss, "The resistance factor to Plasmodium vivax in blacks. The Duffy blood group genotype, FyFy," New England Journal of Medicine, vol. 295, no. 6, pp. 302-304, 1976.

[24] Enquête démographique et de Santé du Mali, Macro International Inc, Calverton, Md, USA, 2007. 


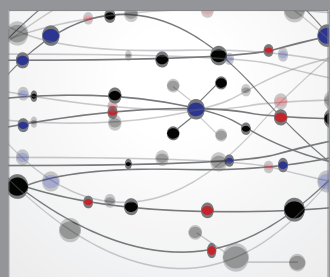

The Scientific World Journal
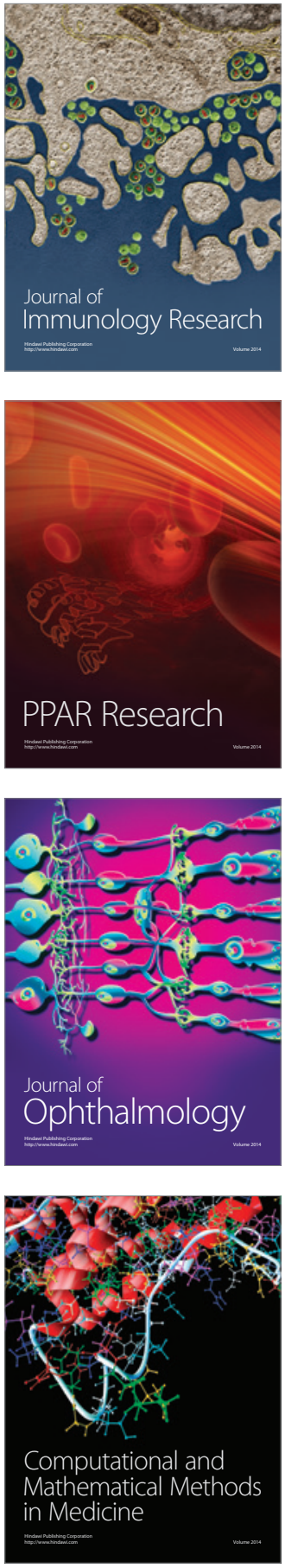

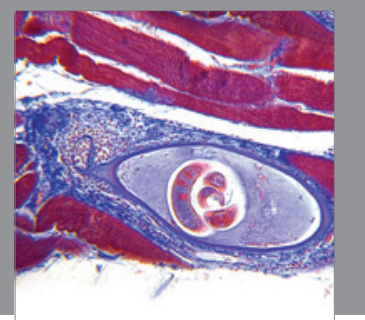

Gastroenterology

Research and Practice
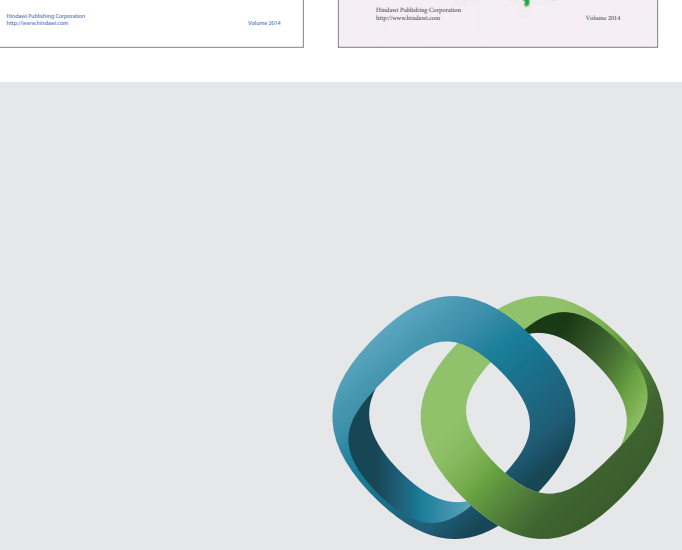

\section{Hindawi}

Submit your manuscripts at

http://www.hindawi.com
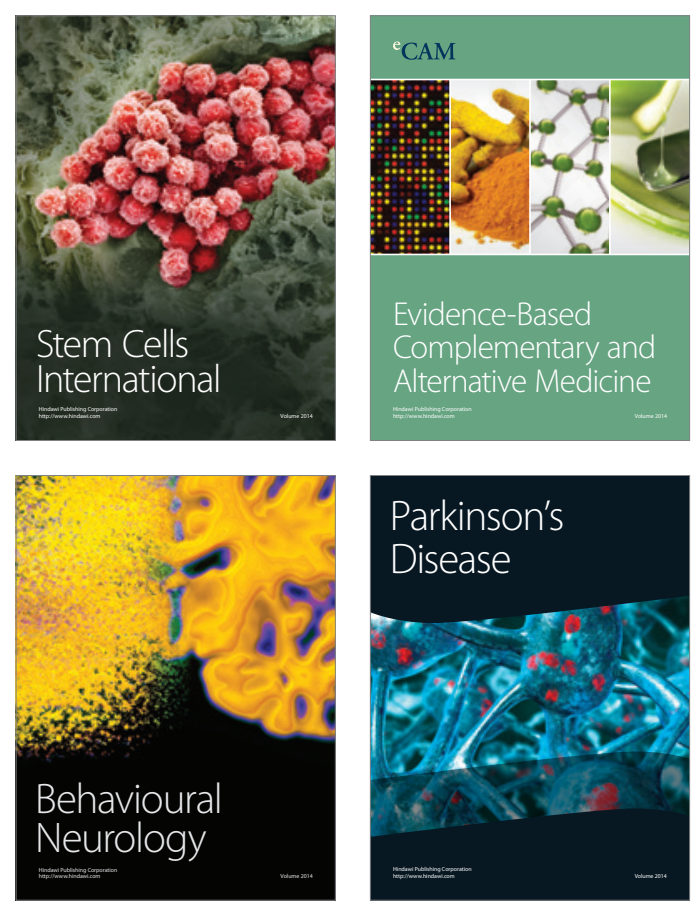

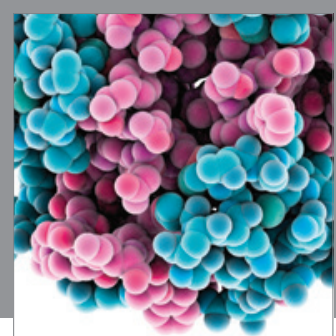

Journal of
Diabetes Research

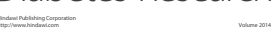

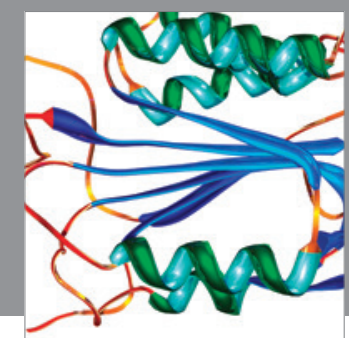

Disease Markers
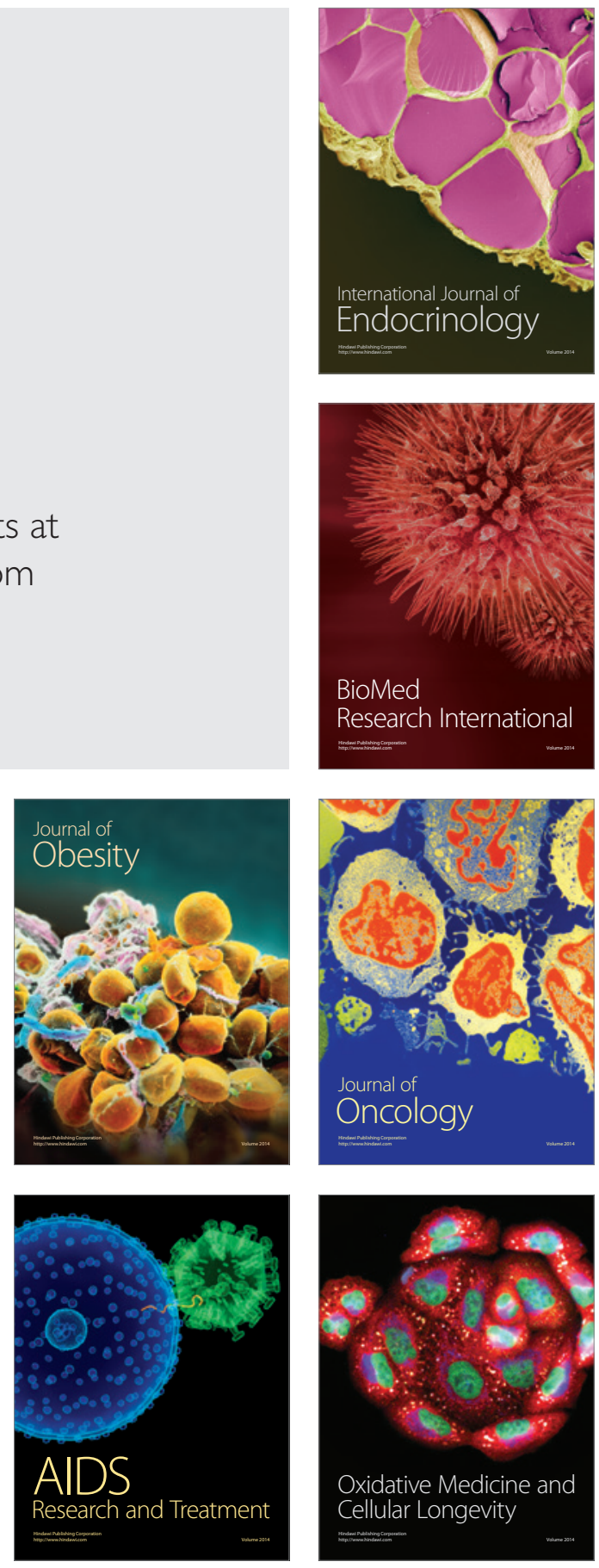